\title{
Pelatihan Pengembangan
}

Sekolah Siaga Bencana untuk Anak Penyandang Disabilitas MTs LB/A Yaketunis, Kecamatan Mantrijeron, Kota Yogyakarta

Bambang Pramono ${ }^{1}$, Danang Febriyantoko ${ }^{2}$ Program Studi Desain Interior, Fakultas Seni Rupa, ISI Yogyakarta E-mail: ${ }^{1}$ bambang.pramono@isi.ac.id, ${ }^{2}$ danangfebriyantoko.df@gmail.com 


\begin{abstract}
Abstrak
Yogyakarta merupakan daerah yang rawan terhadap ancaman bencana alam termasuk bencana gempa bumi. Anak-anak merupakan kelompok rentan yang sering kali menjadi korban ketika benca terjadi, terutama anak-anak disabilitas, termasuk penyandang tunanetra. Yaketunis merupakan lembaga pendidikan formal yang khusus diperuntukkan bagi anak dan remaja penyandang disabilitas dalam hal keterbatasan penglihatan. Sekolah memiliki peranan penting dalam upaya membangun kesiapsiagaan menghadapi bencana. Di dalam kesiapsiagaan menghadapi bencana tentunya dibutuhkan pengetahuan yang baik mengenai risiko bencana yang dapat terjadi. Dalam praktiknya beberapa materi pelajaran terkait kebencanaan dapat diberikan di selasela materi pembelajaran, namun hal tersebut masih perlu dikembangkan demi terwujudnya sekolah siaga bencana di lingkungan Yaketunis. Pelatihan ini diberikan kepada siswa MTsLB/A Yaketunis dengan tujuan agar siswa dengan kebutuhan khusus mempunyai pengetahuan mengenai kesiapsiagaan menghadapi bencana dengan cara menganalisis kerentanan yang ada di sekolah yang kemudian mengetahui tempat yang dirasa aman sebagai tempat berlindung ketika terjadi bencana. Metode yang digunakan yakni mengikuti proses pembelajaran orientasi dan mobilitas yang telah diajarkan oleh pihak sekolah kemudian mengkombinasikanya dengan pengetahuan mengenai manajemen kebancanaan dengan cara menaganalisis spot-spot yang ada di sekolah untuk lebih mengenali lingkungan fisik siswa. Hasil pelatihan menunjukkan bahwa kemampuan siswa dalam mengenali lingkungan sekolah dapat lebih dioptimalkan dengan penggunaan peta jalur evakuasi bencana yang telah diberi huruf braile, sehingga pada saat mata pelajaran orientasi dan mobilitasi peta tersebut dapat digunakan sebagai rujukan untuk lebih mngenali lingkungan fisik serta membekali diri mereka dalam kesiapsiagaan menghadapibencana.
\end{abstract}

Kata kunci: MTsLB/A Yaketunis, siaga bencana, orientasi, mobilitas

\title{
High Disaster-Alertness School Development Workshop for Disabled Students Yaketunis, Mantrijeron District, Yogyakarta City
}

\begin{abstract}
Yogyakarta is a region prone to earthquake and other natural disasters. Children are usually the risque ones that often become victim at times of disaster, especially the disabled ones, e.g. blind. Yaketunis is a formal education association that specializes in the education for disabled children and teens in regard of blindness. This school has an important role in building alertness against disasters. This eventually leads to the need of good knowledge of the possible risks resulting from disasters. In its practice, several education materials about disasters are given in-between their formal lessons, yet these still need improvement to create an alertness against disasters in Yaketunis environment. This workshop is given to Yaketunis special high school with the aim for the disabled students to have awarness and alertness of prospective disasters by knowing which parts of the school pose risks for them and to distinguish which places are safe to be used as shelter in times of need. The
\end{abstract}


method used in this workshop is to combine the orientation and mobilization that have been taught by the school with the knowledge of disaster alertness management to analyze spots at school so they are more aware of their surroundings physically. The results show that students' understanding to their school environment can be optimized with the use of evacuation map written in braile, so that the lesson for orientation and mobilization can be dedicated to that map reading as a guide to understand their surrounding and to equip them with safety measures in times of disasters.

Keyword: Yaketunis Disabled Specialized School, disaster-alertness, orientation, mobilization

\section{PENDAHULUAN}

Rentetan bencana alam besar sering menimpa Indonesia dalam interval waktu yang relatif pendek. Yogyakarta merupakan daerah yang rawan terhadap ancaman bencana alam termasuk bencana gempa bumi. Terakhir kali Yogyakarta terjadi gempa bumi tektonik dengan skala 5,9 SR pada tahun 2006 yang menyebabkan ribuan korban jiwa, kerugian harta benda serta lumpuhnya lini-lini kehidupan. Anak-anak merupakan kelompok rentan yang sering kali menjadi korban ketika benca terjadi, terutama anak-anak disabilitas, termasuk penyandang tunanetra.

Yaketunis merupakan lembaga pendidikan formal yang khusus diperuntukkan bagi anak dan remaja penyandang disabilitas dalam hal keterbatasan penglihatan. Disebutkan oleh Utami, Winarti, \& Purwanto (2014), Yaketunis merupakan kependekan dari Yayasan Kesejahteraan Tunanetra Islam. Yayasan ini dibentuk oleh Supardi Abdusomat pada 12 Mei 1924. Abdusomat yang juga seorang penyandang tunanetra berpendapat bahwa harkat dan martabat difabel sangat dipandang sebelah mata. Oleh karena itu, perlu diupayakan pemberian bekal pengetahuan bagi tunanetra agar bisa hidup percaya diri dan mandiri sehinggadapat berkarya dan mengembangkan potensi yang dimiliki (Utami et al., 2014: 60). MTsLB/A Yaketunis merupakan salah satu pendidikan SLB di Yaketunis. Terdapat 28 orang siswa yang dibina di yayasan ini dengan latar belakang yang berbeda-beda. Kegiatan yang berlangsung di Yaketunis ialah kegiatan belajar-mengajar yang berlangsung dari hari Senin hingga Sabtu. Selain kegiatan belajarmengajar, di Yaketunis juga terdapat fasilitas asrama yang disediakan untuk siswa.

Sekolah memiliki peranan penting dalam upaya membangun kesiapsiagaan menghadapi bencana. Di dalam kesiapsiagaan menghadapi bencana dibutuhkan pengetahuan yang baik mengenai resiko bencana yang dapat terjadi. Sebagai satuan pendidikan Yaketunis memiliki tanggung jawab menyelanggarakan pendidikan agar siswa mampu mengembangkan potensi diri dan membangun budaya termasuk budaya kesiapsiagaan menghadapi bencana. Dalam praktiknya beberapa materi pelajaran terkait kebancanaan dapat diberikan di sela-sela materi pembelajaran, namun hal tersebut masih perlu dikembangkan demi terwujudnya sekolah siaga bencana di lingkungan Yaketunis

Sosialisai akan pentingnya sekolah siaga bencana beberapa kali pernah 
dilakukan di Yaketunis diantaranya dilakukan oleh Perkumpulan Lingkar terhadap guru-guru di lingkungan sekolah pada tahun 2015, hasil dari sosialisasi tersebut diharapkan guru-guru dapat membina, membimbing serta mengarahkan siswa apabila bencana terjadi. Sosialisai tersebut masih perlu terus dikembangkan demi terwujudnya sekolah siaga bencana. Melalui pembinaan UKM Seni dari ISI Yogyakarta khususnya dari Program Studi Desain Interior ini diharapkan dapat meningkatkan kesiapsiagaan seluruh komponen yayasan termasuk siswa tunanetra agar dapat memiliki pamahaman yang baik mengenai manajemen kebencanaan.

Sardegna menjelaskan bahwa tunanetra merupakan individu yang kehilangan kemampuan melihat karena kedua matanya tidak awas seperti halnya mata pada orang normal (dalam Harimukhti \& Dewi, 2014: 65). Berdasarkan tingkat gangguan atau hambatan dalam penglihatannya, tunanetra terbagi atas dua jenis, yaitu totally blind atau buta total, dan low vision atau yang masih mempunyai sisa penglihatan (Pratama et al., 2016:15). Anak tunanetra mengalami keterbatasan dalam hal penerimaan informasi, pada anak dengan kondisi normal informasi dapat diperoleh melalui indera pengelihatan, sedangkan pada anak penyandang tunanetra informasi tersebut dapat diterima melalui indera lain seperti indera penciuman, peraba dan perasa. Masih terbatasnya media informasi kebencanaan menyebabkan anak dengan tunanetra kesulitan mengakses atau mendapatkan informasi sehingga mengurangi kesiapsiagaan siswa dalam menghadapi bencana.
Pelatihan yang diberikan kepada siswa MTsLB/A Yaketunis bertujuan agar siswa dengan kebutuhan khusus mempunyai pengetahuan mengenai kesiapsiagaan menghadapi bencana dengan cara menganalisa kerentanan yang ada di sekolah yang kemudian mengetahui tempat yang dirasa aman sebagai tempat berlindung ketika terjadi bencana.

Pelatihan ini memberikan pengetahuan dan keterampilan yang mendukung peningkatan kesiapsiagaan menghadapi bencana dengan cara (1) pengenalan lingkungan sekolah/asrama yang rentan terhadap bencana berupa pelatihan orientasi dan mobilitas dengan menganalisis spot-spot di sekolah (2) pembuatan peta evakuasi bencana sekolah berhuruf braille yang dapat digunkan oleh siswa tunanetra. Diharapkan, pelatihan ini dapat bermanfaat bagi siswa Yaketunis dalam menambah pengetahuan serta kesiapsiagaan menghadapi bencana alam, sehingga apabila terjadi bencana mereka dapat mengetahui tindakan apa yang harus dilakukan serta kemana harus belindung. Pelatihan yang merupakan bagian dari tri darma perguruan tinggi ini pun diharapkan dapat menjadi sarana untuk mensosialisasikan hasil-hasil riset dan pengetahuan yang dimiliki oleh dosen kepada masyarakat umum.

\section{METODE PENGABDIAN}

Khalayak Sasaran yang menjadi objek penyuluhan ini adalah siswa-siswa kelas VIII MTsLB/A Yaketunis yang telah menerima pelajaran orientasi dan mobilitas dengan gangguan pengliahatan low vision maupun kebutaan total, yag berjumlah 13 orang. 
Kegiatan dilaksanakan di MTsLB/A Yaketunis yang beralamat di Jalan Parangtritis Nomor 46, Kecamatan Mantrijeron, Kota Yogyakarta, Provinsi Daerah Istimewa Yogyakarta. Adapun waktu pelaksanaan penyuluhan yaitu pada tanggal 3 April 2017 sampai dengan 20 Mei 2017.

Metode yang digunakan yakni mengikuti proses pembelajaran orientasi dan mobilitas yang telah diajarkan oleh pihak sekolah kemudian mengkombinasikanya dengan pengetahuan mengenai manajemen kebancanaan dengan cara menaganalisis spotspot yang ada di sekolah untuk lebih mengenali lingkungan fisik siswa. Kendala yang dihadapi berupa sempitnya lahan sekolah, sehingga kegiatan orientasi dan mobilitasi dikembangkan keluar sekolah. Dengan demikian titik kumpul yang ditetapkan apabila terjadi bencana, berada di luar lingkungan sekolah.

Selanjutnya, kegiatan penyuluhan dimulai dengan pemberian materi penyuluhan yang berupa orientasi dan mobilitasi. Orientasi merupakan peroses penggunaan seluruh komponen indera yang masih ada untuk mementukan posisi seseorang terhadap benda-benda penting yang ada di sekitarnya. Adapun mobilitas merupakan kemampuan untuk bergerak dari satu posisi tetap menuju posisi yang diinginkan di bagian lain dari lingkungan yang sama. Prinsip-prinsip orientasi dan mobilitas adalah bahwa pada akhirnya penyandang tunanetra terlatih untuk bertanya pada dirinya sendiri sebelum bergerak untuk berjalan dan melawati, dengan pertanyaan tentang: where am $i$ (dimana saya berada?), where is my objective (kemana tujuan saya?), dan how do $i$ get there (bagaimana saya samapai ke sana?). Dari jawaban atas pertanyaan tersebut, penyandang tunanetra dapat membuat suatu rencana perjalanan. Mereka perlu mengetahui ciri-ciri medan dan beberapa petunjuk yang dapat membantu.

Materi berikutnya yaitu manajemen bencana sekolah. Menurut Undang-Undang Nomor 24 Tahun 2007 Pasal 1 tentang Penanggulangan Bencana, kesiapsiagaan adalah "serangkaian kegiatan yang dilakukan untuk mengantisipasi bencana melalui pengorganisasian serta melalui langkah yang tepat guna dan berdaya guna". Ini di antaranya mencakup pengembangan/ peningkatan keseluruhan strategi kesiapan, kebijakan, struktur institusional, peringatan dan kemampuan meramalkan, serta rencana yang menentukan langkah- langkah yang dicocokkan untuk membantu komunitas yang berisiko menyelamatkan hidup dan aset mereka dengan cara waspada terhadap bencana dan melakukan tindakan yang tepat dalam mengatasi ancaman yang akan terjadi atau bencana sebenarnya. Kemampuan tersebut juga dapat dinalar melalui adanya simulasi regular dengan kerja sama berbagai pihak terkait yang dilembagakan dalam kebijakan lembaga pendidikan tersebut untuk mentransformasikan pengetahuan dan praktik penanggulangan bencana dan pengurangan risiko bencana kepada seluruh warga sekolah sebagai konstituen lembaga pendidikan.Tabel 1 berikut ini menerangkan jenis-jenis kegiatan yang dilakukan dalam kegiatan penyuluhan ini beserta materi yang diberikan. 
Tabel 1 Jadwal Kegiatan dan Materi Kegiatan

\begin{tabular}{|c|c|c|}
\hline Pertemuan & Kegiatan & Tanggal/Lokasi \\
\hline 1 & $\begin{array}{l}\text { Materi dasar tentang Sekolah } \\
\text { Siaga Bencana (Kerentanan } \\
\text { Sekolah) }\end{array}$ & 3 April / Yaketunis \\
\hline 2 & $\begin{array}{l}\text { Praktik observasi lapangan } \\
\text { bersama-sama }\end{array}$ & 7 April /Yaketunis \\
\hline 3 & \multirow{6}{*}{$\begin{array}{l}\text { Latihan menganalisis spot- } \\
\text { spot sekolah yang memiliki } \\
\text { kerentanan terhadap bencana/ }\end{array}$} & 13 April /Yaketunis \\
\hline 4 & & 20 April/Yaketunis \\
\hline 5 & & 21 April/Yaketunis \\
\hline 6 & & 28April /Yaketunis \\
\hline 7 & & 4 Mei / Yaketunis \\
\hline 8 & & $5 \mathrm{MEI} /$ Yaketunis \\
\hline 9 & \multirow{3}{*}{$\begin{array}{l}\text { Membuat peta kerentanan } \\
\text { sekolah }\end{array}$} & 12Mei / Yaketunis \\
\hline 10 & & $18 \mathrm{Mei} /$ Yaketunis \\
\hline 11 & & 19 Mei /Yaketunis \\
\hline 12 & $\begin{array}{l}\text { Praktik penggunaan desain } \\
\text { media }\end{array}$ & $20 \mathrm{Mei} /$ Yaketunis \\
\hline
\end{tabular}

Tabel 2 Foto-Foto Kegiatan

\begin{tabular}{|l|l|l|}
\hline No & \multicolumn{1}{|c|}{ Keterangan } & Foto \\
\hline 1 & $\begin{array}{l}\text { Kondisi kelas dalam kegiatan belajar } \\
\text { mengajar }\end{array}$ & \\
\hline
\end{tabular}




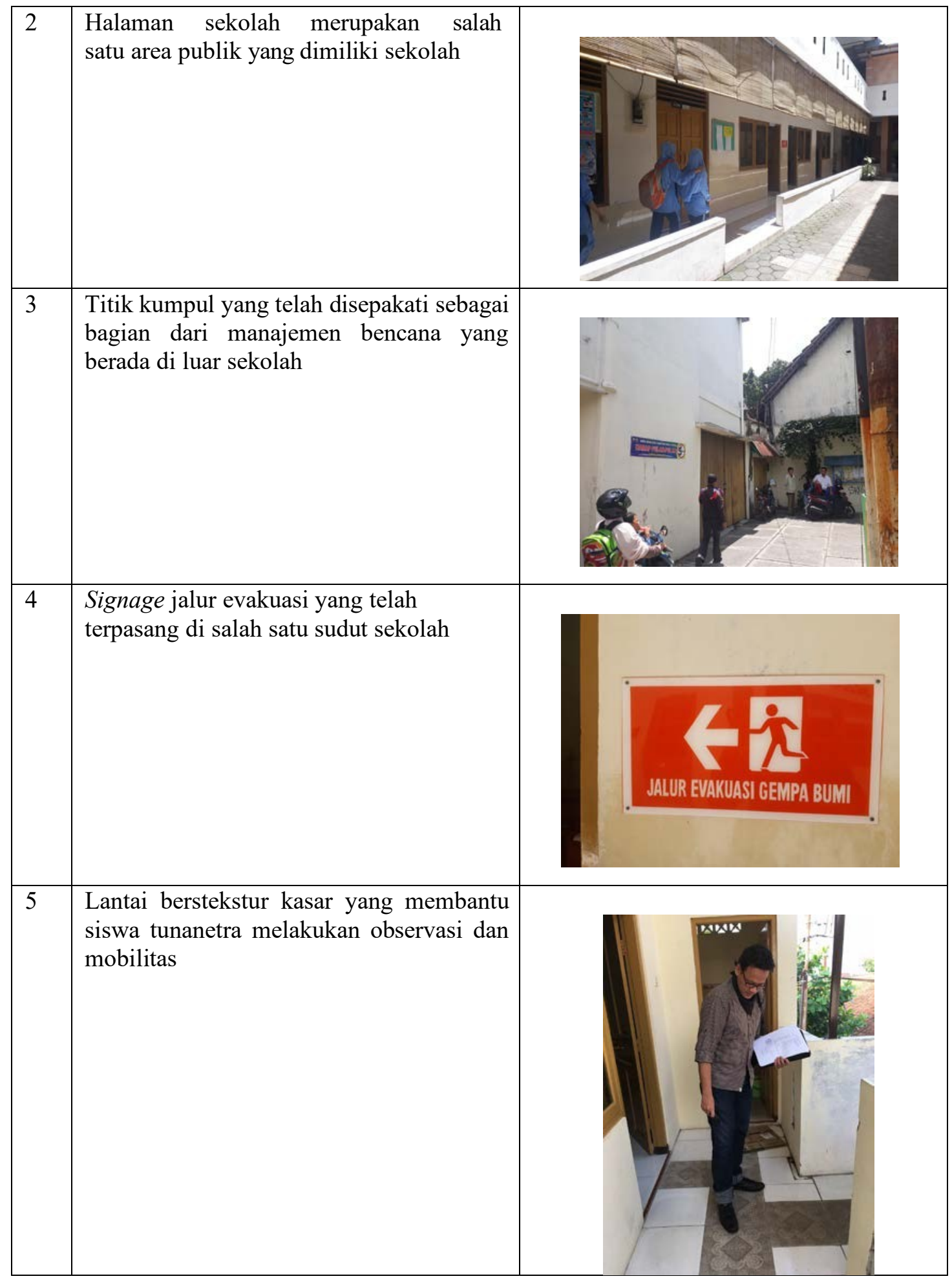




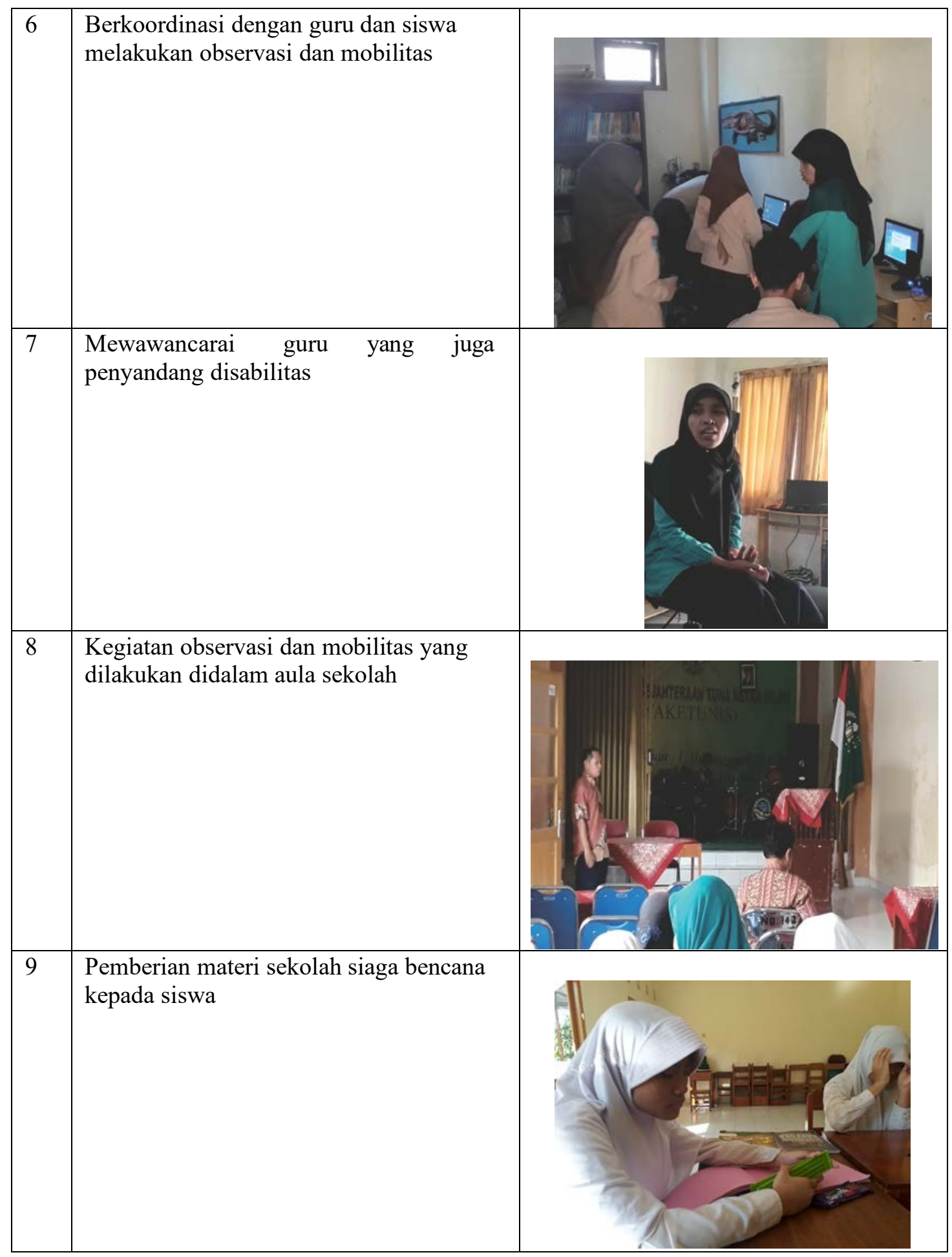




\begin{tabular}{|l|l|l|}
\hline 10 & $\begin{array}{l}\text { Praktik observasi menganalisis spot- } \\
\text { spot yang rentan di sekolah }\end{array}$ \\
\hline 11 & $\begin{array}{l}\text { Salah satu rambu evakuasi yang berada di } \\
\text { halaman sekolah }\end{array}$ & $\begin{array}{l}\text { Praktik penggunaan peta evakuasi } \\
\text { bencana }\end{array}$ \\
\hline 12 &
\end{tabular}

\section{HASIL DAN PEMBAHASAN}

Siswa kelas VIII MTsLB/A Yaketunis telah memahami lingkungan sekolahnya dengan baik. Hal ini dibuktikan dengan kemampuan mereka untuk menelusuri daerah luar sekolah kemudian kembali menuju sekolahnya serta mampu mengindentifikasi spot- spot yang memungkinkan terjadinya bahaya di lingkungan sekolahnya.

Materi pelajaran orientasi dan mobilitas yang biasa rutin diberikan setiap hari Jumat memberi bekal kepada siswa dalam mengenali lingkungan sekolahnya. Penelusuran tiap ruang di sekolah kemudian dikombinasikan dengan pengetahuan 
mengenai kesiapsiagaan terhadap bencana, sehingga siswa memahami daerah yang berpotensi bahaya ketika terjadi bencana.

Setelah melakukan penulusuran lingkungan sekolah tahap selanjutnya adalah membuat peta/denah rencana evakuasi yang dapat dibaca dan dipahami oleh siswa tunanetra. Pembuatan peta evakuasi tersebut diawali dengan memberi teori pengetahuan mengenai sekolah siaga bencana, apa itu bencana, bagaimana, apa bahayanya, tandatandanya, dan apa yang harus dilakukan untuk mengahadapinya.

Pembuatan peta evakuasi bencana dibantu oleh guru mata pelajaran orientasi dan mobilitasi, dengan menambahkan huruf braile terhadap rencana peta yang telah dibuat. Diharapkan dengan penambahan huruf braile tersebut dapat membatu siswa tunanetra untuk membaca peta. Penamaan tiap-tiap ruang kelas akan menggunakan huruf braile, sebagai penanda tiap ruang dalam peta siswa dituntut untuk lebih mengenali lingkunganya terkait dengan kedekatan antarruang dan aksesibilitas untuk menuju ruang yang dituju maupun titik kumpul yang telah ditentukan.

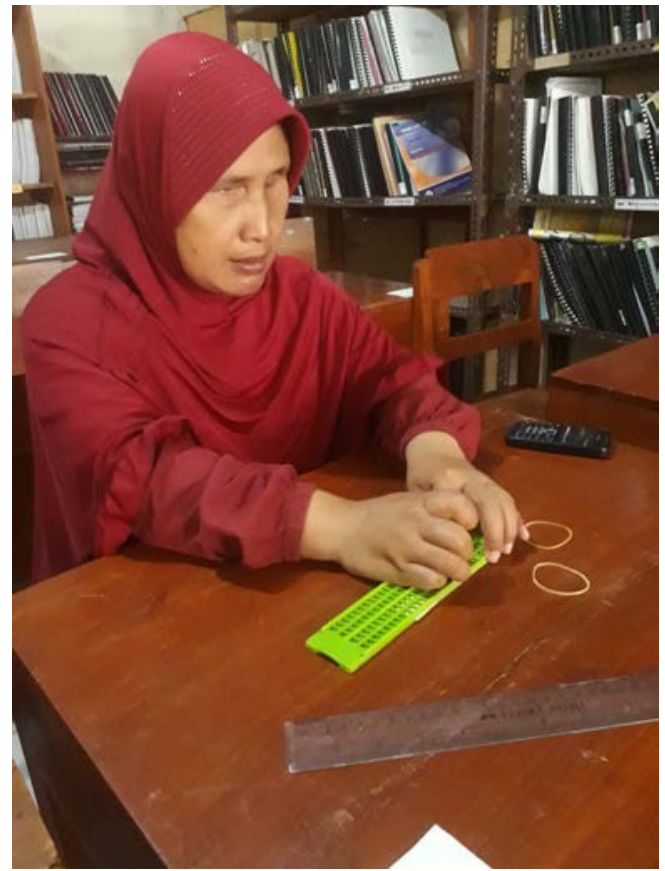

Gambar 1 Membuat huruf braile pada peta dibantu oleh guru mata pelajaran orientasi dan mobilita

\section{DENAH JALUR EVAKUASI GEMPA BUMI} MTS YAKETUNIS

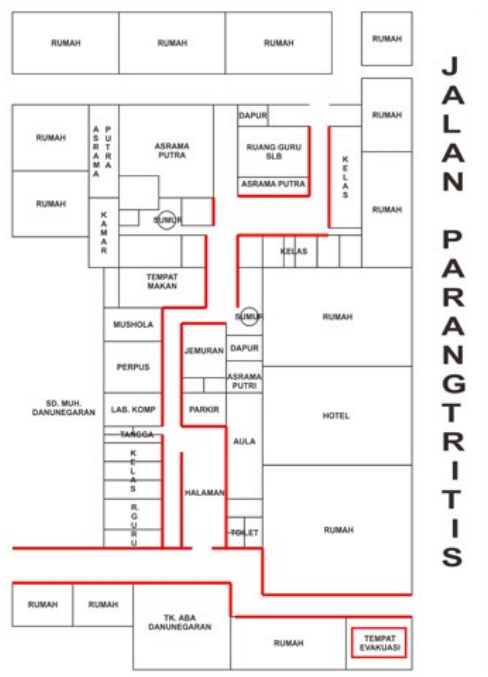

Gambar 2 Rencana peta /denah jalur evakuasi bencana gempa bumi 


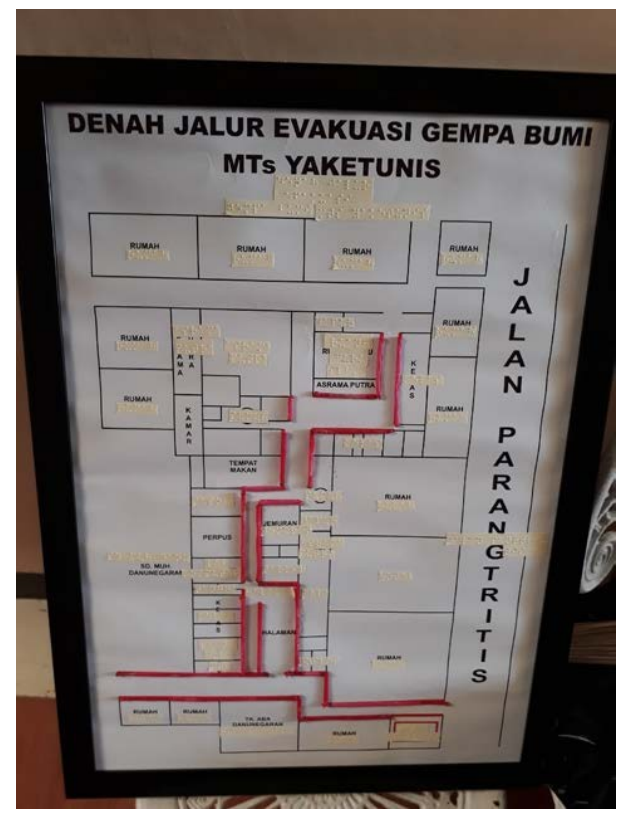

Gambar 3 Denah jalur evakuasi yang telah ditambahkan huruf braile

\section{KESIMPULAN}

Secara umum siswa telah mampu mengidentifikasi lingkungan fisik sekolahnya, pengetahuan mengenai kebencanaan telah diketahui oleh siswa termasuk kesiapsiagaan menghadapi bencana, apa yang harus dilakukan pada saat bencana terjadi, dan dimana tempat yang harus dituju sebagai titik kumpul. Kemampuan mengenali lingkungan sekolah dapat lebih dioptimalkan dengan penggunaan peta jalur evakuasi bencana yang telah diberi huruf braile sehingga pada saat mata pelajaran orientasi dan mobilitasi peta tersebut dapat digunakan sebagai rujukan untuk lebih mengenali lingkungan fisiknya serta membekali diri dalam kesiapsiagaan menghadapi bencana

\section{SARAN}

Pendidikan kebencanaan termasuk di dalamnya manajemen kebencanaan harus terus-menerus dievaluasi dan dilatih oleh seluruh komponen sekolah, dibutuhkan kesadaran baik guru maupun siswa untuk terus membekali diri menghadapi bencana yang sewaktu- waktu dapat terjadi.

\section{UCAPAN TERIMA KASIH}

Terima kasih kepada Lembaga Pengabdian kepada Masyarakat Institut Seni Indonesia Yogyakarta atas kesempatan yang diberikan untuk melaksanakan penyuluhan ini. Terima kasih pula kepada Kepala Sekolah MTsLB/A Yaketunis yang telah membantu kelancaran dan berperan serta dalam pelaksanaan penyuluhan ini.

\section{DAFTAR PUSTAKA}

Harimukhti, M. T., \& Dewi, K. S. (2014). Eksplorasi Kesejahteraan Psikologis Individu Dewasa Awal Penyandang Tunanetra. Jurnal Psikologi Undip, 13(1/April).

Pratama, D., Hakim, D. A., Prasetya, Y., Febriandika, N. R., Trijati, M., \& Fadhillah, U. (2016). Rancang Bangun Alat dan Aplikasi untuk Para Penyandang Tunanetra Berbasis Smartphone Android.

Utami, R., Winarti, \& Purwanto, J. (2014). Rancang Bangun Perangkat Eksperimen Hukum Arcimedes untuk MTs LB/A Yaketunis Kelas VIII. Inklusi, I(1/Januari). 